\title{
Vivência de familiares de crianças com transtornos mentais
}

\author{
Experiences of families that have children with mental disorders \\ Vivencia de familiares de niños con trastornos mentales
}

\section{Eliane Rosso', Miriam Aparecida Nimtz ${ }^{\mathrm{II}}$, Marcio Roberto Paes ${ }^{\mathrm{III}}$,Mônica Macedo ${ }^{\mathrm{IV}}$, Mariluci Alves Maftum ${ }^{\mathrm{V}}$,Camila Bonfim de Alcantara ${ }^{\mathrm{VI}}$}

\begin{abstract}
Resumo: Objetivo: descrever a vivência de familiares de crianças com transtornos mentais. Método: pesquisa qualitativa, com o método história oral temática híbrida realizada com oito familiares em um Centro de Atendimento Educacional Especializado. Os dados foram coletados de março a maio de 2017, mediante entrevista semiestruturada. Resultados: emergiram duas categorias: Emoções, sentimentos e dificuldades vivenciadas por familiares de crianças com transtornos mentais; e, Suporte de apoio familiar, social e de saúde à criança com transtornos mentais. Os familiares referiram cansaço, desgaste, culpa e insegurança, evidenciando mudanças importantes na dinâmica familiar após o diagnóstico de transtorno mental. Considerações finais: os familiares carecem de informações sobre o transtorno mental, apresentam necessidade de adaptar a rotina familiar para atender à criança, e apoio de familiares, amigos, professores e outros profissionais para que consigam cuidar de seu ente.
\end{abstract}

Descritores: Saúde mental; Família; Transtornos mentais; Criança; Enfermagem

Abstract: Objective: to describe the experiences of members of families that have children with mental disorders. Method: qualitative research, with the hybrid oral thematic history method carried out with eight family members in a Specialized Educational Service Center. Data were collected from March to May 2017, via semi-structured interviews. Results: two categories emerged: Emotions, feelings and difficulties experienced by family members of children with mental disorders; and, Support for family, social and health support for children with mental disorders. The family reported tiredness, exhaustion, guilt and insecurity, revealing important changes in the family dynamics

\footnotetext{
${ }^{\text {I }}$ Enfermeira, Mestre em Enfermagem, Docente colaboradora da Universidade Estadual do Centro Oeste. Guarapuava, Paraná, Brasil. E-mail: eliane_ros@yahoo.com.br.Orcid: https://orcid.org/0000-0002-1794-2606

II Enfermeira, Doutora em Enfermagem, Docente adjunto do departamento de enfermagem e docente colaboradora do programa de pósgraduação em enfermagem, Universidade Federal do Paraná (UFPR). Curitiba, Paraná, Brasil. E-mail: miriamnimtz@uol.com.br . Orcid: https://orcid.org/0000-0001-7491-5789

III Enfemeiro, Doutor em enfermagem, Docente adjunto do departamento de enfermagem da UFPR. Curitiba, Paraná, Brasil. E-mail: marropa@ufpr.br. Orcid: http://orcid.org/0000-0003-0305-1500

IV Terapeuta ocupacional, Doutora em Psicologia, Docente adjunta do departamento de terapia ocupacional da UFPR. Curitiba, Paraná, Brasil. E-mail: terapeutamonica@ hotmail.com. Orcid: https://orcid.org/0000-0002-6831-4490

${ }^{v}$ Enfermeira, Doutora em enfermagem, Docente permanente do programa de pós-graduação em enfermagem, UFPR. Curitiba, Paraná, Brasil. E-mail: Maftum@ufpr.br. Orcid: https://orcid.org/0000-0001-8706-7299

VI Discente de enfermagem, Bolsista de iniciação científica CNPq, UFPR, Curitiba, Paraná, Brasil. E-mail: cbalcantara47@gmail.com. Orcid: https://orcid.org/0000-0001-8175-9569
} 
following the diagnosis of mental disorder. Final considerations: family members lack information about mental disorders; need to adapt the family routine to attend to the child; and require support from family, friends, teachers and other professionals so that they can take care of their child.

Descriptors: Mental health; Family; Mental disorders; Child; Nursing

Resumen: Objetivo: describir la vivencia de familiares de niños con trastornos mentales. Método: pesquisa cualitativa, con el método historia oral temática híbrida realizada con ocho familiares en un Centro de Atención Educacional Especializado. Los datos han sido recogidos de marzo a mayo de 2017, a través de entrevista semiestructurada. Resultados: han surgido dos categorías: Emociones, sentimientos y dificultades vividas por familiares de niños con trastornos mentales; y, Soporte de apoyo familiar, social y de salud a los niños con trastornos mentales. Miembros de la familia han informado cansancio, desgaste, culpa e inseguridad, evidenciando cambios importantes en la dinámica familiar después del diagnóstico de trastorno mental. Consideraciones finales: los familiares carecen de informaciones sobre el trastorno mental, necesitan adaptarse a la rutina familiar para atender las necesidades de los niños, y apoyo de familiares, amigos, profesores y otros profesionales para que logren cuidar de su ser querido.

Descriptores: Salud mental; Familia; Trastornos mentales; Niños; Enfermería

\section{Introdução}

A saúde mental das crianças brasileiras foi considerada como problema de saúde pública recentemente, pois o tema era atribuído aos setores educacionais. Entretanto, com o Movimento da Reforma Psiquiátrica que vem ocorrendo desde os anos de 1978, os serviços de saúde passaram a ser responsabilizados pelo cuidado da saúde mental infantil, sendo um dos promotores da superação do caráter excludente do cuidado a essa população específica. ${ }^{1}$

O envolvimento da família no cuidado à saúde mental das crianças também é recente, e aqui se entende a família como a expressão máxima da vida privada, considerada como um lugar de intimidade, em que são construídos sentidos e expressões de sentimentos assim como se exterioriza o sofrimento psíquico que se impõe a vida dos seres humanos. Também é percebida como espaço de afeto e de relações que são imprescindíveis para a socialização dos indivíduos, que por esse convívio desenvolvem o sentimento de pertencimento a relações que os incluem na vida em sociedade..$^{2-4}$

A estrutura familiar pode ser abalada de forma significativa na ocorrência de transtornos mentais em crianças, atingindo, principalmente, a autoestima dos pais, porque pode representar 
3 | Rosso E, Nimtz MA, Paes MR, Ignácio MMM, Maftum MA, Alcantara CB

falha no processo de criação. O pouco conhecimento sobre os transtornos mentais e o estigma social atribuído à sua ocorrência na infância, acentuam as dificuldades vivenciadas pelos familiares e resultam no sofrimento de todo o núcleo familiar..$^{2-5}$

O abalo familiar também está relacionado ao papel social atribuído à criança, pois por possuir estreita relação de dependência com os pais, seu adoecimento pode levar à união ou à desestruturação parental. ${ }^{5-6}$ Estima-se que 10 a $20 \%$ das crianças sofram com transtornos mentais, dessas, 3 a 4\% requeiram tratamento intensivo. Nessa população são mais frequentes o autismo, a psicose infantil e os transtornos de ansiedade..$^{4-7}$

No Brasil, poucos são os dados específicos sobre as principais causas de atendimento emergencial em saúde mental. No que se refere à infância, são mais frequentes alterações comportamentais sem diagnóstico estabelecido, relato de comportamento suicida diagnóstico de depressão e agressividade, situações de abuso de drogas e situações de violência. ${ }^{7-9}$

Também é importante considerar a mudança de percepção quanto ao status social da infância e adolescência ao longo da história, pois há a compreensão de que se trata de indivíduos que se encontram em fase de desenvolvimento e que desde o nascimento são cidadãos detentores de direitos. O marco desta mudança é a promulgação da Lei n 8.069, de 13 de Julho de 1990, que dispõe sobre o Estatuto da Criança e do Adolescente (ECA). ${ }^{10-11}$

$\mathrm{Na}$ tentativa de suprir esses direitos, várias ações foram instituídas, entre elas iniciativas na área da educação, da assistência social, no ambiente jurídico e no da saúde. Esse último buscou atender às necessidades das crianças e suas famílias por meio da implantação na atenção primária de Programas de Saúde da Criança e na atenção especializada, na oferta de atendimento em ambulatórios de saúde mental e no estabelecimento de Centros de Atenção Psicossocial Infantil (CAPSi), nas cidades com capacidade para tal serviço conforme especificidade da legislação vigente. ${ }^{10}$ 
Quando o transtorno mental ocorre em uma criança, faz-se necessário a disponibilização de mais tempo da família para desempenhar o cuidado e isso leva a modificações na dinâmica familiar. Há mudanças no modo de organizar a vida, na relação dos indivíduos com o trabalho, na relação entre pais e os filhos, bem como na relação conjugal, necessitando, ainda, em algumas situações, de controle financeiro para poder propiciar melhor tratamento ao filho. Dessa forma, os familiares podem vivenciar desgaste físico e emocional, com impacto mais significativo para a pessoa que é a referência no cuidado da criança. ${ }^{1,12}$

Considerando o impacto dos transtornos mentais no núcleo familiar, é importante que os serviços de saúde e os profissionais da área compreendam toda a unidade familiar como o objeto de cuidado, ou seja, todos os membros da família e a relação familiar em si devem ser considerados no planejamento da assistência, pois só assim será possível ofertar cuidado integral, o qual deve ser dar por meio de atendimento multidisciplinar realizado por equipe multiprofissional. Também devem ser consideradas estratégias que auxiliem na promoção do vínculo familiar. ${ }^{6,13}$

O enfermeiro, como parte integrante da equipe de saúde, pode desempenhar um papel fundamental na assistência à criança e seus familiares, pois por meio da estreita relação com estes e o estabelecimento de vínculo terapêutico, oportuniza a expressão de pensamentos, sentimentos e dúvidas sobre os transtornos e o tratamento psicossocial. ${ }^{1,6}$ Além disso, estratégias como a escuta e conversa terapêutica auxiliam o enfermeiro na identificação das necessidades mais emergentes da criança e seus familiares, bem como suas carências a médio e em longo prazo. Tais estratégias são fundamentais porque possibilitam o planejamento do cuidado de forma individualizada, considerando tanto as demandas dos familiares quanto da própria criança. ${ }^{6,14}$

Contemplam a assistência de enfermagem em saúde mental, ações de orientação e educação em saúde, com o objetivo de auxiliar os familiares a compreender a fisiopatologia dos 
5 | Rosso E, Nimtz MA, Paes MR, Ignácio MMM, Maftum MA, Alcantara CB

transtornos mentais e as diferentes abordagens terapêticas propostas. Ao fazer isto, instrumentalizam os familiares para realizar o cuidado da criança de modo a incentivar e promover seu desenvolvimento pessoal com autonomia e independência. Estas atividades também auxiliam os familiares e a criança a encontrar estratégias para o manejo dos sinais e sintomas dos transtornos, inclusive sobre ações a serem tomadas em situações de crise, manifesta pela agudização da sintomatologia. ${ }^{1,6,15}$

Reconhecendo a importância dessa temática, se considera que estudos com o foco nos familiares que vivenciam o cotidiano com a criança com transtornos mentais, são relevantes no sentido de contribuir com evidências científicas que subsidiem a prática da enfermagem. Assim, nesta pesquisa, buscou-se responder à questão de pesquisa "Como é a vivência de familiares de crianças com transtornos mentais?” A resposta a essa questão vai ao encontro do objetivo deste estudo, o qual consiste em descrever a vivência de familiares de crianças com transtornos mentais.

\section{Método}

Trata-se de pesquisa qualitativa centrada no método da história oral temática híbrida, realizada em um Centro de Atendimento Educacional Especializado, localizado no município de Guarapuava-Paraná.

Este serviço integra a RAPS no município e é destinado a ofertar assistência em saúde e apoio pedagógico às crianças com comorbidades mentais, por meio de atendimento médico especializado em psiquiatria e neurologia, bem como assistência multiprofissional, através de equipe composta por psicólogos, fonoaudiólogos, psicopedagogos e orientador educacional. Também podem integrar a equipe, terapeuta ocupacional e assistente social. ${ }^{16}$

Esta abordagem metodológica possibilita a investigação de experiências, percepções e vivências de indivíduos ou grupos coletivos acerca de uma realidade, acontecimentos e ou 
fenômenos, considerando os aspectos subjetivos que, embora, ricos de significado e sentido, não podem ser mensurados de forma quantitativa. Por meio da coleta de materiais narrativos é possível capturar e registrar o significado das vivências aos indivíduos que participam de um processo social. ${ }^{17}$

O método da história oral possui três abordagens distintas, sendo elas a história oral de vida, a temática e a tradição oral. Para esta pesquisa optou-se pela abordagem temática, a qual também se subdivide em híbrida e pura. Considerando que a primeira valoriza a construção do percurso narrativo e a segunda possui enfoque em assuntos específicos, identificou-se como adequada a abordagem do tipo híbrida. Assim, o método deste estudo, a história oral temática híbrida, possui um foco central que justifica que no ato da entrevista seja feito um recorte e condução do projeto com mais objetividade, por meio do uso de questionário, permitindo o estabelecimento de critérios para a abordagem de temas, cooperando para o andamento da investigação elencada e alcance da resposta para o objetivo proposto. ${ }^{17}$

Participaram desta pesquisa, familiares que convivem com crianças com transtornos mentais em tratamento. O período de abordagem e o convite para participação no estudo ocorreram entre os meses de março a maio de 2017. Foram convidados todos os familiares que se encontravam cadastrados no serviço. O convite ocorreu às quartas feiras, entre às $8 \mathrm{~h}$ e $10 \mathrm{~h}$, período em que ocorriam as consultas do psiquiatra, havendo presença de maior número de familiares de crianças com transtornos mentais.

Os critérios de inclusão foram: ser familiar da criança que apresente diagnóstico e encontre-se em atendimento no Centro de Atendimento Educacional Especializado (considerarse familiar a pessoa que se dedica aos cuidados da criança, seja pai, mãe, avôs ou outro membro da família; com ou sem vínculo consanguíneo) e como critério de exclusão, ser familiar com idade inferior a 18 anos. O estudo apresentou 13 recusas, de modo que a amostra final foi composta por oito familiares, dos quais dois eram pais e seis mães, com idade entre 25 a 48 anos. 
Os dados foram coletados mediante entrevista individual com o apoio de instrumento semiestruturado, elaborado pelos autores, composto por questões abertas que versavam sobre a vivência com a criança com transtornos mentais. As narrativas foram gravadas com auxílio de gravador digital de aparelho celular, em local reservado dentro do próprio serviço em horário de disponibilidade dos participantes.

Para a análise dos dados, foram seguidas três fases, sendo a primeira denominada de transcrição absoluta, em que são mantidas as palavras ditas em estado bruto, mantêm-se também a estrutura de perguntas e respostas, bem como as repetições, erros e palavras sem peso semântico. A segunda fase é a textualização, em que são eliminadas as perguntas, excluídos os erros gramaticais e corrigidas as palavras sem peso semântico. Os sons e ruídos são eliminados em favor de um texto mais claro e liso. Nesse momento, é escolhida uma frase guia denominada de “tom vital”, pois contém a essência de sentido do discurso. ${ }^{17}$

A terceira fase, denominada transcrição, consiste na apresentação do texto em sua versão final, o qual deve ser lido e autorizado pelo autor do discurso, após isto irá compor a série de entrevistas do projeto. Nesta fase há a aproximação entre o sentido e a intenção original do que é dito pelos entrevistados. Destaca-se que as entrevistas, se analisadas isoladamente, não são consideradas como história oral, dessa forma, o processo de análise implica em cruzar as diversas lógicas internas de cada relato que fazem com que se resolva a proposta indicada no projeto, ou seja, a análise implica não na divisão racional das entrevistas, mas sim, a partir do todo fazer a definição dos temas relevantes. ${ }^{17}$

Em conformidade com as recomendações da Resolução n. 466 de 12 de dezembro de 2012, foram assegurados o sigilo e o anonimato da identidade dos envolvidos, o livre acesso às informações coletadas e o acesso ao produto final, bem como o direito à desistência, a qualquer momento, da pesquisa; caso manifestassem esse desejo. ${ }^{18} \mathrm{Ainda}$, depois de prestados os esclarecimentos a respeito da pesquisa e da participação, foi solicitado que assinassem o Termo 
de Consentimento Livre e Esclarecido, e a Carta de cessão dos direitos. Este estudo foi aprovado por meio de parecer emitido pelo Comitê de Ética em Pesquisa, COMEP-UNICENTRO, sob o número 1.814.756, em 08 de novembro de 2016.

\section{Resultados}

A partir da análise emergiram temas que favoreceram a descrição da vivência de familiares de crianças com transtornos mentais.

\section{Emoções, sentimentos e dificuldades vivenciadas por familiares de crianças com transtornos mentais}

Os pais, por vezes, expressaram cansaço e desgaste ao dizer que não sabiam mais o que fazer, como lidar com a situação de ter um filho com transtornos mentais, ficando evidente que o comportamento dos filhos faz com que se sintam constrangidos e envergonhados. O sentimento de culpa figurou com frequência nos relatos, bem como medo e vergonha:

Senti-me culpado, se eu tinha errado em algum lugar, não tinha dado atenção que chega, porque a psicóloga me disse que eu tinha que ficar perto, presente, dar atenção. Só que nem sempre é fácil, eu preciso trabalhar e têm vezes que eu pego serviço em outra cidade e tenho que viajar, tento não ficar muito tempo fora e voltar sempre no fim de semana. (F1 Pai)

Senti-me desorientada, com vergonha, perdida, culpada, com medo, e se ela tenta essa loucura de novo, o que vou fazer? E essa coisa que ela escuta? Meu Deus!' Eu não sei o que dizer quando ela fala que ouviu ou que sonhou com aquele maldito cara de preto sem rosto. Fui ao colégio falar com a diretora para contar o que estava acontecendo. Isso não foi fácil. Como que eu ia chegar lá e falar que minha filha estava louca? A gente fica sem saber o que fazer. Dá uma vergonha. (F2 Mãe) 
Eu passo vergonha quando vou à festa de familia ou de amigos, porque ele não sai de perto da mesa. Não dá para descuidar que senão ele guarda comida nos bolsos. (F5 Mãe)

Os relatos dos familiares mostram que após o diagnóstico, houve uma mudança em suas atitudes e sentimentos em relação ao comportamento da criança, seja aumentando o sentimento de responsabilidade desses pais, seja por meio de uma percepção nova da realidade. Alguns familiares destacaram a importância de receberem apoio profissional para auxilia-los durante este processo de aceitação do diagnóstico e a compreensão do transtorno como uma patologia que requer tratamento. Ainda, apontam que após este processo houve melhora no relacionamento com a criança. Também manifestam dificuldade em conciliar o cuidado dos outros filhos e manter o relacionamento conjugal, referindo vivenciar desgaste físico e emocional, como demonstrado a seguir:

Tem consulta cada pouco tempo, ele faz terapia toda semana e joga xadrez, ele é muito bom em xadrez. Só que para chegar ao ponto que estamos hoje, nessa aceitação, precisei procurar ajuda, tive que ir para terapia para poder aceitar a doença do meu filho, porque eu não queria acreditar que um filho gerado com tanto amor, carinho e tanta expectativa poderia vir estragado. (F3 Mãe)

Conforme a $B$. foi crescendo a família toda foi se adaptando às necessidades que ela tem. Tem noites que eu sento na cama e sinto o peso que foi o dia, porque eles me sugam. Penso que não posso deixar os outros dois de lado, porque a mais nova precisa mais de mim. Isso acontece, às vezes, e bate uma culpa por não conseguir atender a todos na mesma intensidade. Tem meu marido, também. É raro a gente conseguir sair só nós dois. (F8 Mãe) 
Nós brigamos, mas não é tanto quanto era antes, porque eu tenho mais paciência com ela do que eu tinha antes. O médico disse que é doença e que temos que ter paciência. Fazemos algumas coisas juntas. (F2 Mãe)

\section{Suporte de apoio familiar, social e de saúde à criança com transtornos mentais}

Por meio dos relatos, é possível perceber que algumas pessoas são solicitadas, frequentemente, para apoiar a família no cuidado das crianças com transtornos mentais. Dentre as possibilidades figuram avós, tias, tios, pessoas de confiança contratadas para auxiliar no cuidado à criança, professoras, pedagogas, entre outros. Tais pessoas são solicitadas e acionadas para contribuírem na adaptação da família à nova realidade imposta a partir do diagnóstico. É enfatizada a importância desse suporte para a organização da rotina familiar; assim, pessoas com grau de parentesco são citadas na maioria das entrevistas como apoiadoras no cuidado:

Tenho muita ajuda das minhas irmãs e da "nona”[avó]. Quando não estou trabalhando cedo, faço café para a gente assistir TV [televisão] junto. Minhas irmãs vão fazer faxina. As tias se preocupam bastante com ela, brincam bastante, dão roupa, brinquedo. Tentam fazer ela rir, até ensinar essas coisas de pintar, bordar e dobrar roupa. Essas coisas elas estão ensinando. (F1 Pai)

Na segunda tem aula e tem natação, na terça tem aula e tem aula de xadrez, e quando ele aceita, na terça, de tardezinha ele vai à casa da avó, mas não é sempre que ele está a fim de ir, e temos um acordo em casa de respeitar as vontades dele com relação a isso. (F3 Mãe)

A avó também quer ficar com eles, às vezes, a minha mãe também, porque a mãe dele não mora aqui, mas sempre liga para saber como que eles estão. Alguns sábados que eles ficam na avó e aproveito para lavar o carro, e a mãe deles para fazer as coisas da faculdade. (F4 Pai) 
11 | Rosso E, Nimtz MA, Paes MR, Ignácio MMM, Maftum MA, Alcantara CB

Os professores, o sistema educacional e os profissionais que prestam atendimento no Centro de Atendimento Educacional também são vistos pelos familiares como fonte de apoio. Os familiares percebem na escola um ponto de referência para ajudar no manejo da criança, e depositam expectativas relacionadas a essa ajuda no cuidado às crianças no momento em que estão frequentando a instituição escolar. Fica evidente no discurso dos familiares que apesar da falta de alguns recursos, o Centro de Atendimento Educacional Especializado e seus profissionais foram importantes no processo de aceitação do diagnóstico do transtorno e no direcionamento do tratamento, figurando como um espaço de suporte para as angústias que surgem no dia a dia.

Bem boazinha a professora, preocupada com ela. Todas as professoras do colégio parecem que querem cuidar dela, também. (F1 Pai)

As professoras são realmente muito boas, porque conseguem contornar as situações mais difíceis e estão sempre em contato com a gente e escrevem na caderneta dele se acontecer alguma coisa diferente no dia a dia da escola. Eu sei que lá ele está bem cuidado, acho que maior medo de mãe de filho que precisa de cuidado especial é alguém que cuide com carinho e que não vá judiar, porque eu sei o quanto é preciso ter paciência. (F3 Mãe)

[...] Me encaminharam para o Centro (de atendimento educacional especioalizado) e começou o tratamento, fizeram o diagnóstico que ele come de forma compulsiva e tem ansiedade junto, daí ele começou a ir na psicóloga, mandaram para a nutricionista e o médico "de cabeça" (psiquiatra) passou os remédios. (F5 Mãe)

\section{Discussão}

O impacto do diagnóstico de um transtorno mental impõe aos familiares a necessidade de se adaptar à nova situação, pois essa descoberta, não raro, está permeada por questões estigmáticas e preconceituosas. ${ }^{5}$ Os problemas vivenciados e relatados por estes apresentam 
muitos traços em comum, entretanto cada um deles possui suas individualidades e peculiaridades na forma do sentir, reagir e expressar o que experimentam diante das diversas situações. ${ }^{14,19-20}$

O ato de receber o diagnóstico é importante no processo de aceitação e compreensão do comportamento da criança, aspecto que também contribui para que os familiares obtenham uma nova percepção da realidade, adaptando as expectativas em relação ao crescimento e desenvolvimento de seu ente. Além disto, conhecer a fisiopatologia dos transtornos mentais e a necessidade de diferentes abordagens terapêuticas é fundamental para que também se responsabilizem pela promoção e recuperação em saúde da criança. ${ }^{21}$

Por esse motivo, o enfermeiro e outros profissionais de saúde que atuam na Rede de Atenção Psicossocial (RAPS) precisam ser capazes de ouvir e conhecer as demandas de cada membro da família de forma singular. Também devem estar aptos para orientá-los, esclarecendo as dúvidas sobre os transtornos, contribuindo, assim, para a melhor convivência e aceitação. Familiares orientados, adequadamente, podem ser a base de sustentação da assistência, pois passam a identificar a necessidade de buscar novas formas de se relacionar com a criança e a importância de encontrar estratégias para o manejo das atitudes e comportamentos relacionados aos transtornos, com objetivo de promover seu desenvolvimento pessoal e social com autonomia e independência. ${ }^{14,19-20}$

Contudo, este processo é complexo e pode ser acompanhado de preconceito relacionado ao tipo de transtorno, de modo que a criança pode passar a ser estigmatizada tanto no seio da família como no meio social em que ela transita. Sobretudo no que se refere ao ambiente familiar, a percepção dessa nova realidade pode estar acompanhada pelos sentimentos de desestruturação, desgaste e sobrecarga física e emocional, acometendo, especialmente, a pessoa que se incumbe, diretamente, do cuidado dessa criança. ${ }^{5}$ 
13 | Rosso E, Nimtz MA, Paes MR, Ignácio MMM, Maftum MA, Alcantara CB

A informação de que uma criança necessita de cuidados em saúde mental por tempo indeterminado constitui um grande desafio para a família, o ambiente social e o serviço de saúde pública para o qual está designada sua assistência. De modo que os profissionais que atuam na RAPS devem estar preparados para facilitar a interação entre a tríade criança - família - sociedade, sempre respeitando a subjetividade e peculiaridade socioculturais de cada realidade, contribuindo para o enfrentamento dos transtornos mentais e colaborando para que a sobrecarga familiar diminua. ${ }^{20-22}$

Por mais que o cuidado seja exercido antes do diagnóstico, após os familiares receberem a informação que seu filho apresenta um transtorno mental, esse cuidado se intensifica e passa a ser uma necessidade diária e ininterrupta. ${ }^{5,22} \mathrm{O}$ impacto do transtorno mental no cotidiano atinge vários aspectos da vida familiar, podendo ser considerado como fator de sobrecarga, porque requer que os familiares coloquem as suas necessidades e desejos em segundo plano, interrompam sua rotina e, consequentemente, mudem sua vida. ${ }^{5}$

Estes referem vivenciar emoções e sentimentos que vão desde a vergonha e constrangimento relacionados ao comportamento da criança em público, até a percepção de culpa associada ao surgimento do transtorno e o medo perante a ausência de controle em situações diversas do dia a dia. ${ }^{5,21-22}$ Sentir culpa associada à constatação do transtorno é um dos sentimentos mais externados pelos familiares, esse pensamento recorrente gera um desconforto constante na tentativa de entender o transtorno. ${ }^{19,21}$

Ao assumir o cuidado de um filho com transtornos mentais, por vezes há mudança na estrutura familiar e dessa reestruturação surgem novos papéis; regras passam a existir e situações comuns do cotidiano podem vir a ser percebidas como geradoras de sofrimento. Além das mudanças internas no âmbito familiar, as relações externas também são afetadas, pois diante das limitações impostas pela nova condição, a família redefine seus compromissos, planos, relacionamentos sociais e até mesmo sua forma de interagir com o ambiente social e de trabalho. 
Todo esse processo é desgastante, mas necessário, para que a família, a criança e a sociedade em que estão inseridos possam conviver com os transtornos mentais da melhor forma possível. ${ }^{21}$

Mediante o exposto, pode-se afirmar que os familiares e a criança requerem suporte social por meio de uma ampla rede de apoio composta por diversos membros da família, pelos setores de saúde, educação e assistência social, bem como outros grupos sociais e instituições, que auxiliem no enfrentamento das adversidades que ocorrem no cotidiano e são provocadas pelos transtornos mentais. Poder contar com uma rede de apoio, é poder ampliar o cuidado, pois a família pode lançar mão de outras estratégias para atender às necessidades da criança.6,23-24

O setor de educação consiste em um importante componente da rede social de apoio, pois, com frequência, os profissionais da educação identificam de forma precoce as alterações do comportamento da criança e orientam os familiares a buscar avaliação de saúde e acompanhamento por profissional capacitado. Essa importante relação com o sistema de educação foi demonstrada por um estudo em que este setor foi responsável por quantidade significativa dos encaminhamentos aos serviços de saúde mental, sendo o motivo mais recorrente, dificuldades na aprendizagem e, com menor frequência, comportamento suicida. Os outros motivos de solicitação de avaliação por um serviço especializado em saúde mental foram queixas relacionadas à ansiedade e agressividade..$^{25}$

Outra importante estratégia encontrada pelos familiares que vivenciam o processo de cuidado destas crianças é a articulação social por meio das relações interpessoais do convívio, o que permite buscar apoio de pessoas externas à família, tal como organizações não governamentais e grupos de ajuda que possam ofertar o apoio necessário para superar as barreiras que o transtorno mental impõe. ${ }^{6}$ Desta forma, a rede de apoio além de auxiliar na resolução dos problemas e das dificuldades que surgem diariamente, consiste em um meio de alívio para as tensões cotidianas ao proporcionar o compartilhamento de vivências e a expressão de sentimentos. ${ }^{6,23-24}$ 


\section{Considerações finais}

A vivência com crianças com transtornos mentais, com frequência, é permeada por emoções e sentimentos de medo, culpa, vergonha e cansaço. Há a necessidade de adaptar a rotina familiar para melhor atender à criança e, diante das dificuldades, as relações familiares podem ficar fragilizadas, pois ao priorizar o cuidado daquele com o transtorno, os demais filhos podem ser negligenciados e a relação conjugal ficar comprometida.

A investigação da vivência destes familiares também mostrou que é frequente o sentimento de impotência, expresso por meio da verbalização de não saber como agir diante do comportamento da criança. Isto mostra a importância de uma rede de apoio complexa formada por serviços educacionais e de saúde que sejam capazes de orientar, instruir e auxilia-los no cuidado à criança. Ainda, salienta-se a importância de incentivar a participação de outros membros da família no tratamento e no cuidado, com o objetivo de promover o sentimento de unidade familiar e evitar a sobrecarga física, emocional e financeira de um único membro.

O método da história oral híbrida possibilitou a investigação de tal vivência com aprofundamento de sentido e compreensão de significados. Ao oportunizar aos familiares a expressão de suas emoções, sentimentos, pensamentos e atitudes, também foram estimulados a refletir e re-significar a percepção acerca da realidade que lhes é imposta.

De forma semelhante, o estabelecimento de vínculo terapêutico entre profissional de saúde e paciente/familiares proporciona a manifestação de sentimentos, pensamentos e dúvidas. O enfermeiro, como parte integrante da equipe de saúde, deve valorizar e estimular a expressão tanto da criança quanto de seus familiares, pois esta estratégia auxilia na identificação das fragilidades e potencialidades, as demandas individuais e coletivas bem como as expectativas em relação ao tratamento. Tais informações instrumentalizam o enfermeiro no planejamento de um cuidado integral e singular. 
Destaca-se a importância da realização de pesquisas que abordem a vivência de familiares de crianças com transtornos mentais em várias etapas do tratamento e que considerem as diferentes fases do desenvolvimento infantil, pois os resultados possibilitariam identificar quais as demandas dos familiares e da criança nos diferentes momentos. Também é relevante que seja descrita a vivência dos familiares de acordo com o tipo de transtorno que a criança apresenta, uma vez que há maior estigma social em relação aos transtornos graves e severos e maior dificuldade no manejo dos sintomas.

Espera-se que o presente estudo estimule novas reflexões sobre a temática e incentive outras pesquisas na área. Também é almejado que os resultados apresentados possam subsidiar a prática de enfermagem e da equipe multiprofissional no trabalho com familiares de crianças com transtornos, pois mostram que a oferta de suporte social e de saúde a esta população contribui para seu desenvolvimento pessoal, escolar e social.

\section{Referências}

1. Buriola AA, Vicente JB, Zurita RCM, Marcon SS. Sobrecarga dos cuidadores de crianças ou adolescentes que sofrem transtorno mental no município de Maringá - Paraná. Esc. Anna Nery Rev. Enferm [Internet]. 2016 [acesso em 2018 Fev 07];20(2):344-351. Disponível em: http://www.scielo.br/scielo.php?script=sci_arttext\&pid=S141481452016000200344\&lng=en\&nrm=iso\&tlng=pt. doi: http://dx.doi.org/10.5935/1414-8145.20160047.

2. Estevão AR, Teodoro FC, Pinto MNR, Freire MHS, Mazza VA. A família no cuidado de enfermagem à criança: revisão integrativa. Cogitare enferm [Internet]. 2016 [acesso em: 2019 Mar 28];21(4):01-09. Disponível em: https://revistas.ufpr.br/cogitare/article/view/46551/pdf. Doi:http://dx.doi.org/10.5380/ce.v21i4.46551.

3. Moreno V, Barbora GC. Familiares de pessoas portadoras de transtorno mental: conhecimento dos direitos à saúde. Rev. gaúcha enferm [Internet]. 2015 [acesso em: 2019 Mar 28];36(1):43-8. Disponível em: https://repositorio.unesp.br/bitstream/handle/11449/140690/S1983-14472015000100043pt.pdf?sequence=2\&isAllowed=y. Doi:http://dx.doi.org/10.1590/1983-1447.2015.01.47915.

4. Daltro MCSL, Moraes JC, Marsiglia RG. Cuidadores de crianças e adolescentes com transtornos mentais: mudanças na vida social, familiar e sexual. Saúde Soc [Internet]. 2018 [acesso em 2019 Mar 
28];27(2):544-555. Disponível em: https://www.scielosp.org/article/sausoc/2018.v27n2/544-555/. Doi: http://doi.org/10.1590/S0104-12902018156194.

5. Jackson L, Keville S, Ludlow A. Mothers' experiences of accessing mental health care for their child with an autism spectrum disorder. J Child Fam Stud [Internet]. 2020 [acesso em 2020 Fev 18]; 29:534-545. Disponível em: https://link.springer.com/article/10.1007/s10826-019-01662-8?shared-articlerenderer\#citeas. Doi: https://doi.org/10.1007/s10826-019-01662-8.

6. Brusamarello T, Maftum MA, Alcântara CB, Capistrano FC, Pagliace AGS. Famílias no cuidado à saúde de pessoas com transtorno mental: reflexos do modelo de assistência. Saúde e pesqui [Internet]. 2017 [acesso em 2019 Mar 28];10(3):441-449. Disponível em: http://periodicos.unicesumar.edu.br/index.php/saudpesq/article/view/5993/3127.

Doi:http://dx.doi.org/10.177651/1983-1870.2017v10n3p441-449.

7. Ministério da Saúde (BR). Atenção psicossocial a crianças e adolescentes no SUS: tecendo redes para garantir direitos. Brasília (DF): Ministério da Saúde; 2014.

8. Rossi LM, Marcolino TQ, Speranza M, Cid MFB. Crise e saúde mental na adolescência: a história sob a ótica de quem vive. Cad. Saúde pública [Internet]. 2019 [acesso em 2019 Mar 28];35(3):e00125018. Disponível em: https://www.scielosp.org/pdf/csp/2019.v35n3/e00125018/pt. Doi: 10.1590/0102311X00125018.

9. Martins MMM, Souza J, Silva AA. Crianças e adolescentes usuários de substâncias no serviço de emergência psiquiátrica. Acta paul. enferm [Internet]. 2015 [acesso em 2019 Mar 28];28(1):13-8. Disponível em: $\quad$ http://www.scielo.br/scielo.php?pid=S0103-21002015000100013\&script=sci_arttext\&tlng=pt. Doi:http://dx.doi.org/10.1590/1982-0194201500004.

10. Gomes FMA, Cintra AMO, Ricas J, Vecchia MD. Saúde mental infantil na atenção primária à saúde: discursos de profissionais médicos. Saúde Soc [Internet]. 2015 [acesso em 2018 Fev 07];24(1):244-258. Disponível em: http:/www.scielo.br/scielo.php?script=sci_arttext\&pid=S0104$12902015000100244 \& \operatorname{lng}=$ en\&nrm=iso\&tlng=pt. doi: http://dx.doi.org/10.1590/S0104-12902015000100019.

11. Brasil. Lei n.8.069 de 13 de julho de 1990 (BR). Dispõe sobre o estatuto da criança e do adolescente e dá outras providências. Diário Oficial da União, Brasília (DF) [Internet] 1990 [acesso em 2018 Fev 07]. Disponível em: http://www.planalto.gov.br/Ccivil_03/leis/L8069.htm

12. Campelo LLCR, Costa SME, Colvero LA. Dificuldades das famílias no cuidado à criança e ao adolescente com transtorno mental: uma revisão integrativa. Rev. Esc. Enferm. USP [Internet]. 2014 [acesso em 2018 Fev 07];48(spe):192-198. Disponível em: http://www.scielo.br/scielo.php?script=sci_arttext\&pid=S008062342014000700192\&lng=en\&nrm=iso\&tlng=pt. doi: http://dx.doi.org/10.1590/S0080-623420140000600027. 
13. Vicente JB, Higarashi IH, Furtado MCC. Transtorno mental na infância: configurações familiares e suas relações sociais. Esc. Anna Nery Rev. Enferm [Internet]. 2015 [acesso em 2018 Fev 07];19(1):107-114. Disponível em: http:/www.scielo.br/scielo.php?script=sci_arttext\&pid=S141481452015000100107\&lng=en\&nrm=iso\&tlng=pt. doi: http://dx.doi.org/10.5935/1414-8145.20150015.

14.-Vicente JB, Marcon SS, Higarashi IH. Convivendo com o transtorno mental na infância: sentimentos e reações da família. Texto \& contexto enferm [Internet]. 2016 [acesso em 2018 Fev 07];25(1):e0370014. Disponível em: http:/www.scielo.br/scielo.php?script=sci_arttext\&pid=S010407072016000100314\&lng=pt\&nrm=iso\&tlng=pt. Doi: http://dx.doi.org/10.1590/0104-0707201600370014.

15. Siqueira DF, Botega MSX, Serbim AK, Terra MG. Redes sociais de apoio no cuidado à pessoa com transtorno mental: reflexões. Rev. enferm. UFSM [Internet]. 2018 [acesso em 2019 Mar 28];8(4):859-869. Disponível em: https://periodicos.ufsm.br/reufsm/article/view/26118. Doi:10.5902/2179769226118.

16. Guarapuava. Decreto n. 005 de 24 de janeiro de 2000. Aprova o regimento interno do Centro Municipal de Atendimento ao Portador de necessidades educacionais especiais. Guarapuava, Paraná, Brasil, 2000 [Internet]. [acesso em 2017 mar 12]. Disponível em: http://leismunicipa.is/qhnai

17. Meihy JCSB, Holanda F. História oral: como fazer, como pensar. $2^{\underline{a}}$ ed. 3 reimpressão. São Paulo: Contexto; 2014.

18. Brasil. Ministério da Saúde. Conselho Nacional de Saúde. Resolução n. 466, de 12 de dezembro de 2012 [Internet]. 2012 [acesso em 2018 Fev 07]. Disponível em: http://conselho.saude.gov.br/resolucoes/2012/Reso466.pdf.

19. Brusamarello T, Maftum MA, Mantovani MF, Alcantara CB. Educação em saúde e pesquisa-ação: instrumentos de cuidado de enfermagem na saúde mental. Saúde (Santa Maria) [Internet]. 2018 [acesso em 2019 Mar 28];44(2):1-11. Disponível em: https://periodicos.ufsm.br/revistasaude/article/view/27664. Doi:http://dx.doi.org/10.5902/2236583427664.

20. Noronha AA, Folle D, Guimarães NA, Brum MLB, Schneider JF, Motta MGC. Percepções de familiares de adolescentes sobre oficinas terapêuticas em um centro de atenção psicossocial infantil. Rev. gaúcha enferm [Internet]. 2016 [acesso em 2019 Mar 28];37(4):e56061. Disponível em: https://www.lume.ufrgs.br/bitstream/handle/10183/150385/001008937.pdf?sequence=1\&isAllowed=y. Doi:http://dx.doi.org/10.1590/1983-1447.2016.04.56061.

21. Dovgan KN, Mazurek MO. Differential effects of child difficulties on family burdens across diagnostic groups. J Child Fam Stud [Internet]. 2018 [acesso em 2020 Fev 18];27:872-884. Disponível em: https://ink.springer.com/article/10.1007/s10826-017-0944-9. Doi: https://doi.org/10.1007/s10826-017-0944-9.

22. Souza ALR, Guimarães RA,Vilela DA, Assis RM, Oliveira LMAC, Souza MR et al. Factors associated with the burden of Family caregiver of patients with mental disorders: a cross-sectional study. BMC 
19 | Rosso E, Nimtz MA, Paes MR, Ignácio MMM, Maftum MA, Alcantara CB

psychiatry [Internet]. 2017 [acesso em 2020 Fev 18]; 17:353. Disponível em: https://www.ncbi.nlm.nih.gov/pmc/articles/PMC5655908/. Doi: https://doi.org/10.1186/s12888-017-1501-1.

23. Cattani NA, Ronsani APV, Welter LS, Mello AL, Siqueira DF, Terra MG. Família que convive com pessoa com transtorno mental: genograma e ecomapa. Rev. Enferm. UFSM [Internet]. 2020 [acesso em: 2020 Fev 12];10(e:1-19). Disponível em: https://periodicos.ufsm.br/reufsm/article/view/36517/pdf. Doi https://doi.org/10.5902/2179769236517.

24. Horta ALM, Daspett C, Egito JHT, Macedo RMS. Vivência e estratégias de enfrentamento de familiares de dependentes. Rev. bras. enferm [Internet]. 2016 [acesso em: 2019 Mar 28];69(6):1024-30. Disponível em: http://www.scielo.br/scielo.php?script=sci_abstract\&pid=S003471672016000601024\&lng=en\&nrm=iso\&tlng=pt. Doi:http://dx.doi.org/10.1590/0034-7167-2015-0044 .

25. Cunha MP, Borges LM, Bezerra CB. Infância e saúde mental: perfil das crianças usuárias de um centro de atenção psicossocial infantil. Mudanças, Psicologia da Saúde [Internet]. 2017 [acesso em 2018 Fev 07];25(1):27-35. Disponível em: https://www.metodista.br/revistas/revistasims/index.php/MUD/article/view/7289/5719. doi: http://dx.doi.org/10.15603/2176-1019/mud.v25n1p27-35.

\section{Autor correspondente \\ Eliane Rosso \\ E-mail: eliane_ros@yahoo.com.br \\ Endreço: Rua Jaraguá, n. 190, Bairro Morro Alto, Guarapuava, Paraná, Brasil. \\ CEP: 85065-630}

\section{Contribuições de Autoria}

\section{1 - Eliane Rosso}

Concepção e planejamento do projeto de pesquisa; coleta e análise dos dados; redação do manuscrito e discussão dos dados.

\section{2 - Miriam Aparecida Nimtz}

Concepção e planejamento do projeto de pesquisa; Orientação e supervisão durante a coleta dos dados; Revisão crítica da redação, dos resultados e da discussão dos dados.

\section{3 - Marcio Roberto Paes}

Revisão crítica da redação, dos resultados e da discussão dos dados.

\section{4 - Mônica Macedo}

Contribuições: revisão crítica da redação, dos resultados e da discussão dos dados.

\section{5 - Mariluci Alves Maftum}


Revisão crítica da redação, dos resultados e da discussão dos dados.

\section{6 - Camila Bonfim de Alcantara}

Redação do manuscrito e discussão dos dados.

\section{Como citar este artigo}

Rosso E, Nimtz MA, Paes MR, Ignácio MMM, Maftum MA, Alcantara CB. Vivência de familiares de crianças com transtornos mentais. Rev. Enferm. UFSM. 2020 [Acesso em: Anos Mês Dia]; vol.10 e36: 1-20. DOI:https://doi.org/10.5902/2179769237292 